\title{
A COMPARATIVE OVERVIEW TO DTC FOR PMSM DRIVEN PURE ELECTRIC VEHICLES
}

\author{
Fatih Korkmaz \\ Department of Electric-Electronic Engineering, Çankırı Karatekin University, \\ Uluyazı Kampüsü, Çankırı, Turkey
}

\begin{abstract}
For many industrial applications that including electric motor, selecting of the appropriate motor type is keypoint for the application success and efficiency. This paper presents a comparative performance evaluation between direct torque controlled Brushless AC and Brushless DC motors which have been considered as traction motor on electric vehicles. Moreover, a short review to brushless AC and brushless DC motor technology and vector driver systems are also included. The main structure of the direct torque control method is presented and small-scale pure electric vehicle model is integrated to the motor control model. To make a fair comparison, the brushless AC and brushless DC motors modeled as having the same electrical parameters and simulated with same control model parameters. The simulation studies have shown that direct torque controlled brushless AC and brushless DC motors have similar performance as vehicle traction motor, and both motor types can be considered as a good candidate for electric vehicles applications.
\end{abstract}

\section{KEYWORDS}

PMSM motors, BLAC motor control, BLDC motor control, Electric vehicles, Direct Torque Control

\section{INTRODUCTION}

In 1950s, the availability of high energy density permanent magnets (PMs) and developments in power switching technologies led the development of PM motors[1]. Two typical classifications of permanent magnet synchronous motors (PMSMs) have been presented in literature by scholars according to shape of the induced emf (also known as back emf). One is called as brushless AC (BLAC) which has a sinusoidal-wave back-emf and the other is brushless DC (BLDC) motor which has a trapezoid-wave/square-wave back-emf. A BLDC motor can be defined as a electronic commutated self synchronous rotary motor, where the rotor contains permanent magnet with rotor position sensors. [2] But, it's obvious that same definition easly can be used for the BLAC motors. So far, there has not been a unified standard about the classification or definition of the BLDC motors or BLAC motors.

David C. Wyld et al. (Eds) : DBDM, CICS, CSIP, AI\&FL, SCOM, CSE, CCNET-2016

pp. 29-36, 2016. @ CS \& IT-CSCP 2016

DOI : $10.5121 /$ csit.2016.60503 
The main question that should be asked about the PMSMs is "Why are the PM motors happening more and more popular with every past day?" A PMSM incorporates starting characteristic of serious excitation DC motors and speed-torque characteristic of shunt excitation DC motor. Furthermore, the PMSMs have structural advantages of conventional brushless AC motors[2]. The PMSMs have great advantages like high efficiency, simple structure, high power densities, high starting torque, wide speed ranges, lineer torque and speed characteristics, low maintenance and works in any condition. Due to absence of mechanical brushes and commutator, PMSMs can be acceptable as best choice for high performance drive applications[3]. Hence, it has been preferred motor type in many field such as robotics, vehicle propulsion, aerospace, industrial control, machine tools, etc.

This paper presents an overview to PMSMs and vector drive technologies. Moreover, a comparative performance investigation has been occurred between DTC controlled BLAC and BLDC motors which have been considered as traction motor on electric vehicles. The main structure of the DTC method is presented and small-scale pure electric vehicle model is integrated to the motor control model. The BLAC and the BLDC motors modeled with Simulink as having the same electrical parameters and simulated with same control model parameters to make a fair comparison.

\section{BRUSHLESS SYNCHRONOUS MOTORS}

The AC drive systems can be grouped under two major heading - induction drive systems and synchronous drive systems. Not far, about 3 decades ago, the induction drive systems almost monopolized the whole market, but with the advent of high magnetic permanent magnets, synchronous drive systems, include the PM brushless motors, are becoming popular. [4]

A BLDC motor is designed to be supplied with a trapezoidal shape current while a BLAC with sinusoidal as can be seen in Figure 1. [5]

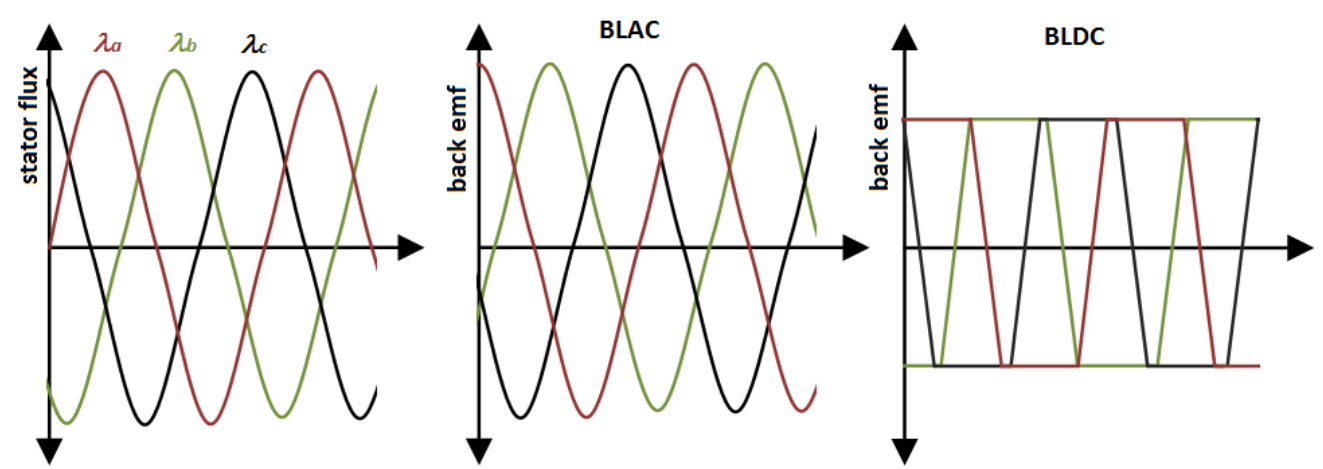

Figure 1. Back emf waveforms of BLAC and BLDC motors

The PM-BLAC motors fed by sinusoidal AC sources and produce an essentially constant torque, or so-called smooth torque. On the other hand, the PM-BLDC motors fed by rectangular or trapezoidal $\mathrm{AC}$ waves and have significant torque pulsations. However, due to interaction between a rectangular field and a rectangular current, the BLDC motors can produce higher torque than the BLAC motor [4]. 
Torque ripples issue is major problem for the many kind of systems, include EVs. The torque ripples causes torsional vibration and also acoustic noise. Due to vibration systems, mechanical parts of the system can be damage, even all system can be breakout [6]. For many years, reduction of the torque ripples in motor control systems have been major research subject and many kind of methods have been proposed by scholars and engineers to overcome this problem [7-9].

\section{DIRECT TORQUE CONTROL}

Direct torque control (DTC) is the name of reliable and energy efficiency vector control method. Although the DTC was originally proposed for asynchronous motors by Takahashi in 1986[10], over the years, it has been applied for various motor type such as linear motor, reluctance motor and also PM motors[11].

Another vector control method which has been preferred in high performance control of motors, is field oriented control (FOC). Almost half a century ago, the FOC method was also firstly proposed for asynchronous motors [12], but today, the FOC has been completely developed and it has been implemented for motor types such as PM motors. Conventional DTC method for AC motors with equations is given in Figure 2.

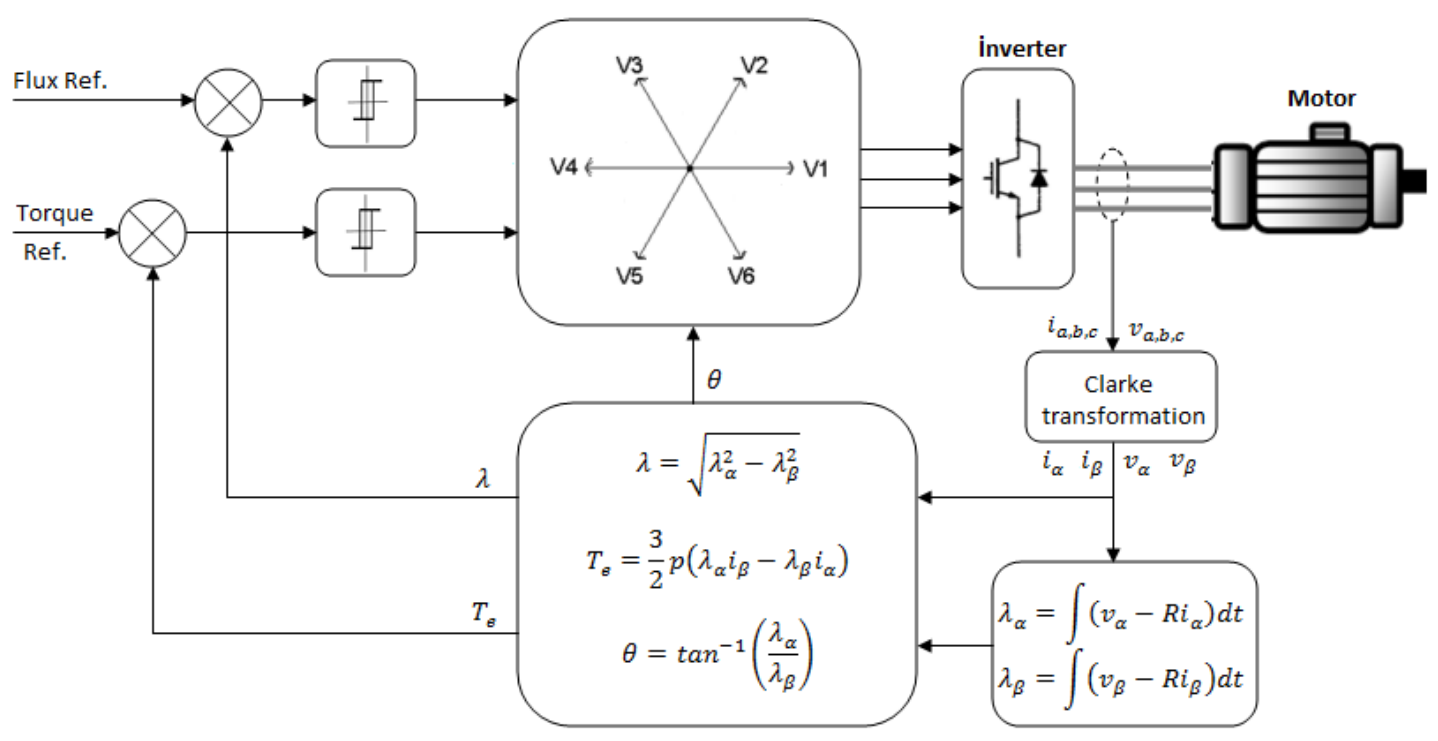

Figure 2. Conventional DTC motor scheme for AC motors

Over the last 40 years, many articles have been published about FOC and DTC of different motor types. However, few articles have focus on similarities or differences of between these methods. [13-15]

Some main structural advantages of the DTC can be listed as follow;

- Does not require current regulator

- Does not require PWM modulator 
- Does not require rotor position measurement

- Does not require complex coordinate transformation

- Less parameter depended

To summarize, it can be pointed out that the DTC has simple structure when compared the FOC. On the other hand, the DTC method has some disadvantages and most important differences against to the FOC is high torque ripples[16].

In [13], the authors presented comparative analysis between two control methods for PMSMs. Advantages and disadvantages of the both methods were compared and discussed. Moreover, simulation based tests were performed for different working conditions. The authors claimed that the DTC had fast dynamic response while the FOC had better torque response and when selecting control method application requirements should be considered.

In another paper [17] the FOC and the DTC controlled PMSM was compared and discussed in detail. As a result, the authors claimed that there were no meaning differences in the main characteristics of the motor for both control method.

A comparisons between the FOC and the DTC controlled PMSMs had also been presented in [14] by numerical simulations. The paper supports almost same the claims with [13]. In other words, numerical simulations proved that the FOC was better on overall torque performance and the DTC had faster dynamic responses.

\section{MOTORS AND CONTROLS ON EVS}

Small-Scale Electric Vehicles (SSEV) are used in personal transportation for short distances. The SSEVs are powered by only battery packs and they only driven by electric motors-pure electric vehicle (PEV)- such as bicycles, scooters, skateboards, toy cars, rail cars, watercraft, forklifts, golf cars, and city cars, etc. The synchronous motors with PM-(BLAC/BLDC) are leading choice for vehicle propulsion in EVs due to advantages that mentioned earlier sections [18].

The DTC method is very useful and appropriate for EVs due to its great advantages such as; controlling torque directly, simple structure and easy applicable, low parameter sensitivity. [19]. To compare of the BLAC and BLDC traction motor performances on the DTC controlled system, Matlab/Simulink models of the controller has been created. Small-scale EV model has also included to model to obtain reference torque parameter for the DTC system. Figure 3 shows Small-scale EV Simulink model.

\section{SIMULATIONS AND RESULTS}

In simulations, BLAC and BLDC driven EV is accelerated to 0-2000 rpm motor speed, and the torque reference value is produced by $\mathrm{EV}$ model. Road angle is $0^{\circ}$ for both motor. Matlab/Simulink block diagram of the DTC model for BLDC motor is given in Fig. 4.

The model and vehicle parameters which have been used in simulation as follows: Vehicle mass: $100 \mathrm{~kg}$, wheel radious: $0.4 \mathrm{~m}$, Ratio of shaft: 1/10, BLAC/BLDC stator resistance: $0.4578 \mathrm{ohm}$, 
BLAC inductances (d-q): $0.003173 \mathrm{H}-0.003507 \mathrm{H}$, Bus voltage of inverter :300V, Flux reference: $0.22 \mathrm{~Wb}$, Flux Hysteresis band: \pm 0.01 , Torque hysteresis band: \pm 0.1 .

The speed (in rad/s) and the torque responses of the motor are presented in Figure 5 - Figure 7.

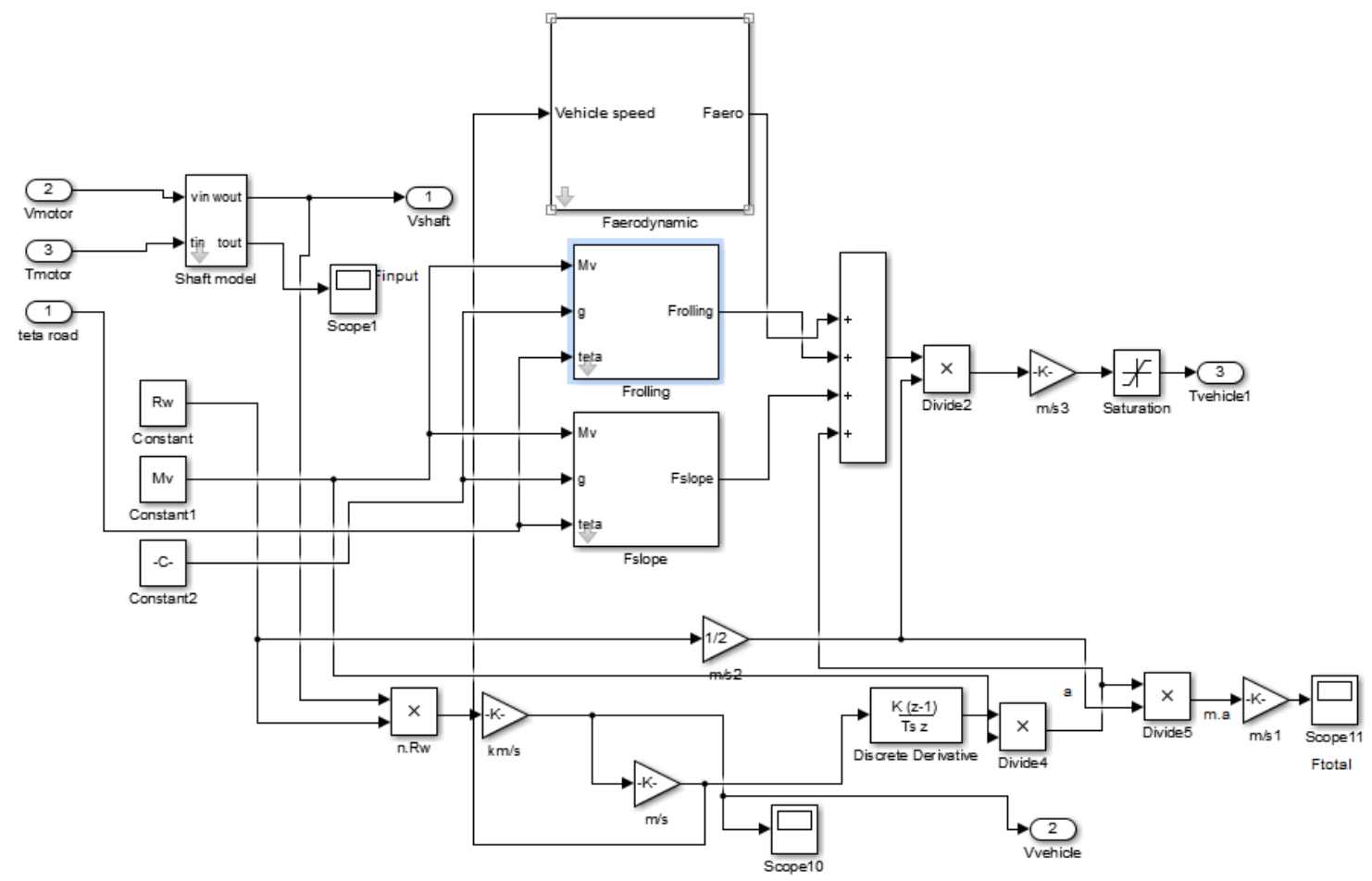

Figure 3. Small-scale EV Simulink model

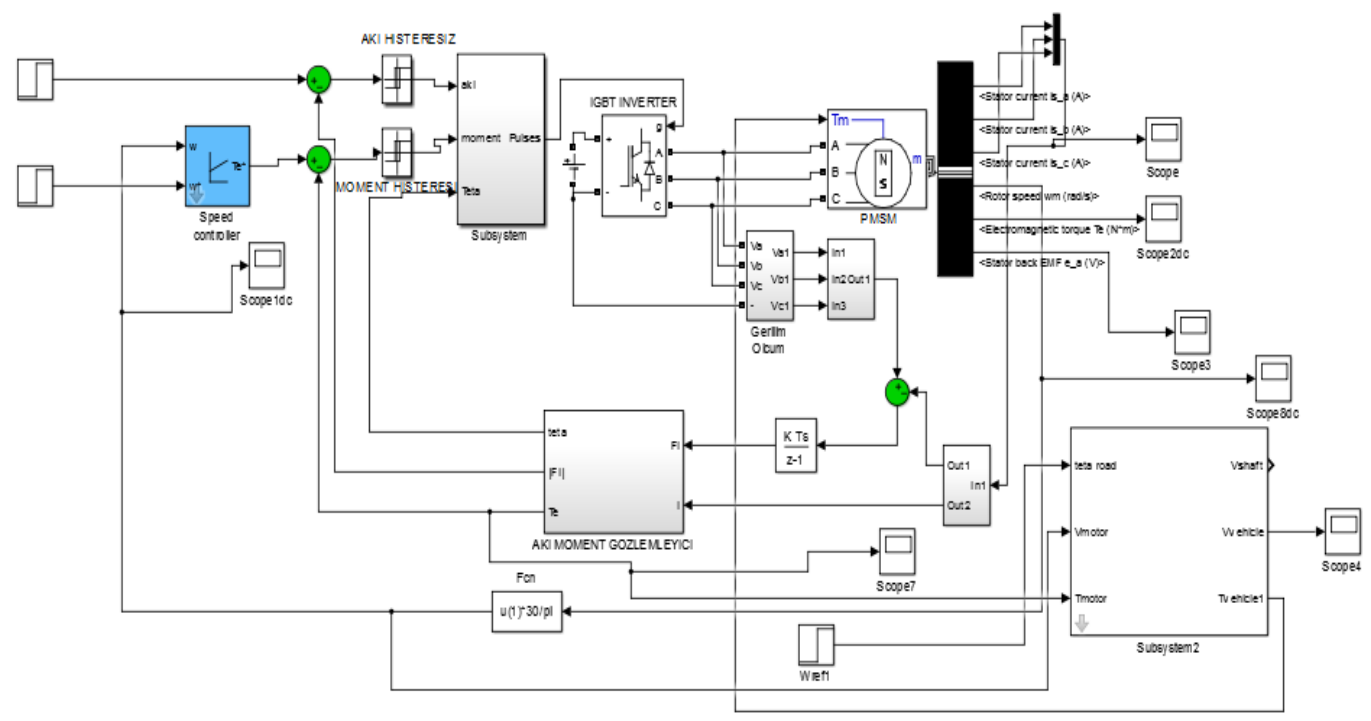

Figure 4. Matlab/Simulink block diagram of the DTC model for BLDC 

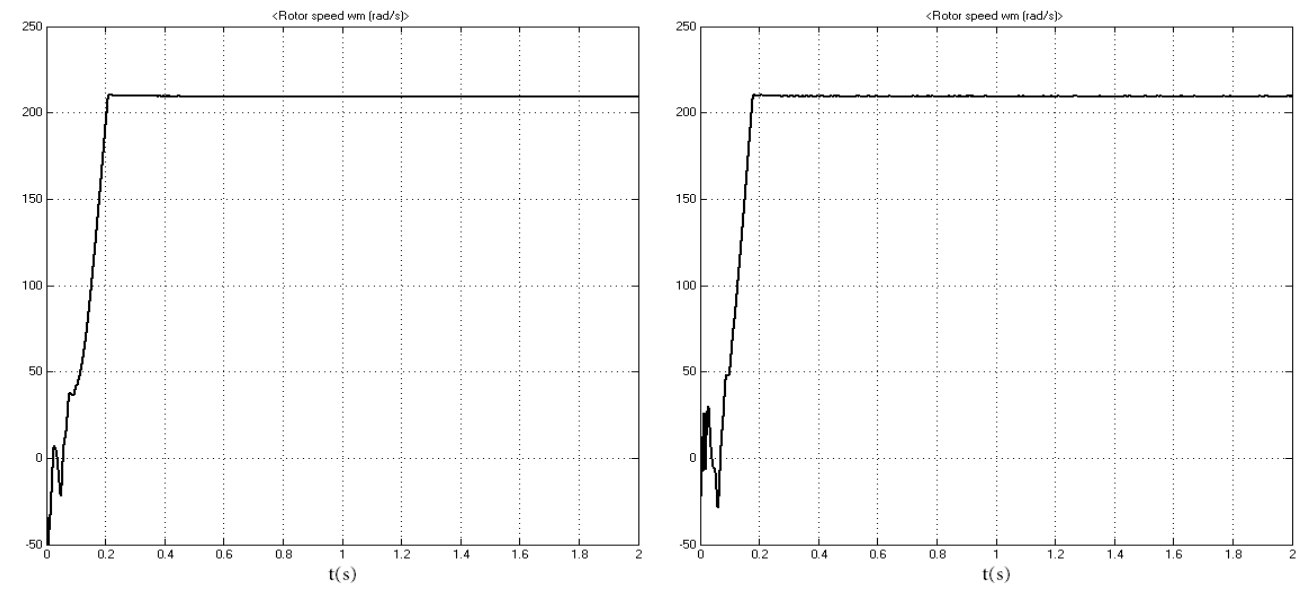

Figure 5. Overview of speed responses of BLAC (leftside) and BLDC (rightside) motors
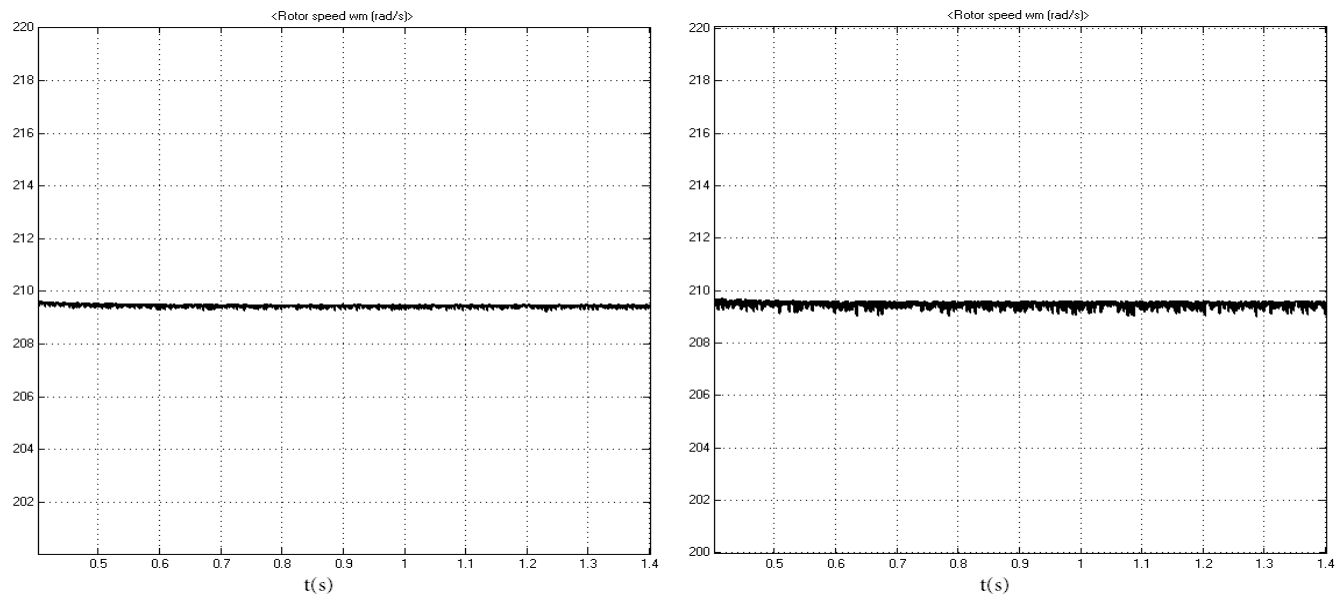

Figure 6. Zoomed view of speed responses of BLAC (leftside) and BLDC (rightside) motors
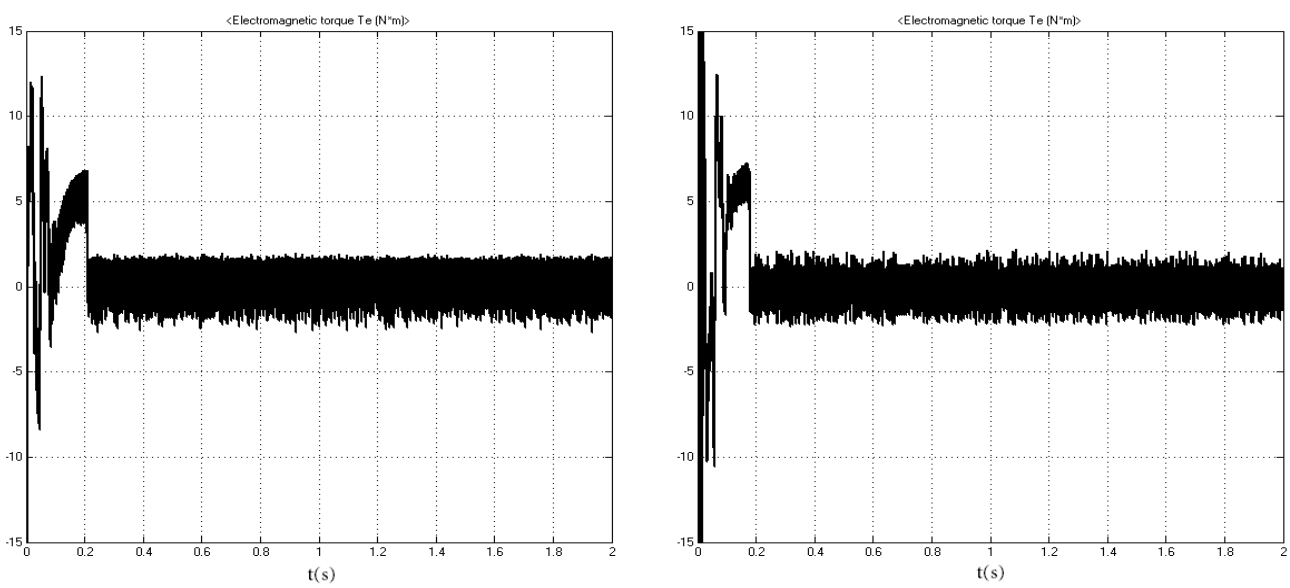

Figure 7. Overview of torque responses of BLAC (leftside) and BLDC (rightside) motors 
When the speed and torque curves of the motor are compared, it can be clearly seen that motor performances are pretty close to each other for both motor types. However, the BLAC motor speed response is better than the BLDC motor due to less ripples (Figure 6.). The simulation studies proof that the DTC method is very appropriate for the BLAC and BLDC motors and vehicle designers/engineers can choice one of the two considering other physical or economical parameters.

\section{CONCLUSiOnS}

Brushless synchronous motors are getting more and more popular every past day due to their well-known advantages like maintenance-free structures, height mass-power ratio, silent works, etc. BLAC and BLDC motors are indispensable motor types for electric vehicle traction systems. This paper aims to present a fair comparison between the BLAC and the BLDC motors for vehicle traction systems. For this purpose, direct torque controlled BLAC and BLDC motor modeled and simulated. The simulation studies show that both motors can be applicable for electric vehicle with DTC method. The speed and torque performances of the motors are almost same. So, it means, when brushless synchronous motor selection is necessary for electric vehicles or similar industrial system, some other physical or economical factors should be taken into consideration.

\section{REFERENCES}

[1] Krishnan, R. Permanent magnet synchronous and brushless DC motor drives, CRC Press, 2010

[2] Chang-liang Xia, Permanent magnet brushless dc motor drives and controls, John Wiley \& Sons Singapore Press, 2012

[3] Purna Chandra Rao, Y. P. Obulesh and Ch. Sai Babu, "Mathematical Modeling of BLDC Motor With Closed Loop Speed Control Using PID Controller Under Various Loading Conditions" ARPN Journal of Engineering and Applied Sciences, vol. 7, no. 10, 2012.

[4] K.T. Chau, Zheng Wang Chaos in electric drive systems : analysis, control and application, 2011

[5] Torres, D., 2009. Comparing motor-control techniques. [Online] Available at: http://www.ecnmag.com/articles/2009/10/comparing-motor-control-techniques [Accessed 05 March 2016].

[6] Z. Q. Zhu and J. H. Leong, "Analysis and Mitigation of Torsional Vibration of PM Brushless AC/DC Drives With Direct Torque Controller," in IEEE Transactions on Industry Applications, vol. 48, no. 4, pp. 1296-1306, July-Aug. 2012.

[7] Fatih Korkmaz, Ismail Topaloglu, Hayati Mamur "Fuzzy logic based direct torque control of induction motor with space vector modulation', International Journal on Soft Computing, Artificial Intelligence and Applications (IJSCAI), Vol.2, No. 5/6, December 2013

[8] S. B. Ozturk, W. C. Alexander and H. A. Toliyat, "Direct torque control of four-switch brushless DC Motor with non-sinusoidal back-EMF," Power Electronics Specialists Conference, 2008. PESC 2008. IEEE, Rhodes, 2008, pp. 4730-4736. 
[9] M. Masmoudi, B. El Badsi and A. Masmoudi, "Direct Torque Control of Brushless DC Motor Drives With Improved Reliability," in IEEE Transactions on Industry Applications, vol. 50, no. 6, pp. 37443753, Nov.-Dec. 2014.

[10] Takahashi, I. \& Noguchi. T. (1986) "A new quick-response and high efficiency control strategy of an induction motor," IEEE Transactions on Industrial Applications, vol.I A-22 ,No.5. , pp. 820-827.

[11] Korkmaz, F., I. Topaloglu, and R. Gurbuz. "Simulink Model of Vector Controled Linear Induction Motor with End Efect for Electromagnetic Launcher System." Elektronika Ielektrotechnika, 2014; 20(1)

[12] Blaschke, F.,(1972) "The Principle of Field Orientation Applied to The New Transvector ClosedLoop Control System for Rotating Field Machines", Siemens-Rev., Vol. 39, 217-220.

[13] X.T. Garcia, B. Zigmund, A. Terlizzi, R. Pavlanin, L. Salvatore "Comparison between FOC and DTC strategies for permanent magnet syncronous motors" Adv Electr Electron Eng, 5 (2012), pp. 76-81

[14] Merzoug, M. S., and F. Naceri. "Comparison of field-oriented control and direct torque control for permanent magnet synchronous motor (pmsm)." Proceedings of world academy of science, engineering and technology. Vol. 35. 2008.

[15] Korkmaz, F., Topaloglu, I., Cakir, M. F., \& Gurbuz, R. (2013, May). Comparative performance evaluation of FOC and DTC controlled PMSM drives. In Power Engineering, Energy and Electrical Drives (POWERENG), 2013 Fourth International Conference on (pp. 705-708). IEEE.

[16] Yilmaz Korkmaz, Fatih Korkmaz, İsmail Topaloğlu, Hayati Mamur"Adaptive bandwidth approach on DTC controlled induction motor"International Journal of Instrumentation and Control Systems, vol : 5 - no : 2,2015

[17] Navid Maleki, Mohammad Reza Alizadeh Pahlavani, Iman Soltani "A Detailed Comparison Between FOC and DTC Methods of a Permanent Magnet Synchronous Motor Drive"Journal of Electrical and Electronic Engineering,2015; 3(2-1): 92-100

[18] James Goss, Mircea Popescu ""Malcolm Burwell - International Performance/cost comparison of induction-motor \& permanent-magnet-motor in a hybrid electric car Copper Association,July 2013 Tokyo Available at: http://www.coppermotor.com/wp-content/uploads/2013/08/Techno-Frontier2013-MBurwell-ICA-EV-Traction-Motor-Comparison-v1.8-Eng1.pdf [Accessed 05 March 2016].

[19] Devender Kumar, Ishan Thakur "A Review on Direct Torque Control for Induction Motor" International Journal of Science and Research (IJSR),Volume 3 Issue 7, July 2014

\section{AUTHORS}

Fatih Korkmaz received the B.S., M.S., and Ph.D. degrees in electrical education from Gazi University, Ankara, Turkey, in 2000,2004 and 2011, respectively. His current major research interests include design, control and applications of motor drive systems. From 2013, he is an assistant professor in Çankırı Karatekin University, Turkey

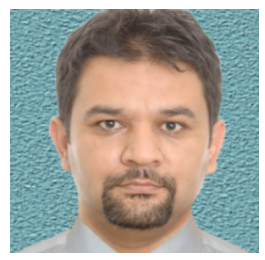

